\title{
Characterization of the infrapatellar fat pad
}

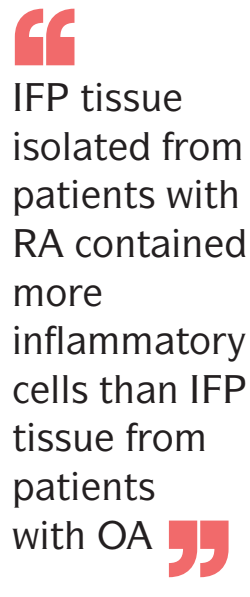

The infrapatellar fat pad (IFP), a fat depot in the knee joint, is thought to have a role in the pathogenesis of osteoarthritis (OA). A new study now characterizes the IFP in rheumatoid arthritis (RA) for the first time.

Studies in OA have shown that intra-articular adipose tissue has a distinct, more pro-inflammatory phenotype than adipose tissue elsewhere in the body, and is suggested to contribute to OA pathogenesis by promoting synovial inflammation and modulating cartilage degradation. "Because most RA joint tissues display a more inflammatory phenotype than their OA counterparts," explains Andreea Ioan-Facsinay, the corresponding author, "we expected to find the same for the IFP."

To this end, the authors compared IFP and synovial tissue of patients with RA $(n=20)$ and OA $(n=51)$. Both the inflammatory cells infiltrating the IFP and synovium and

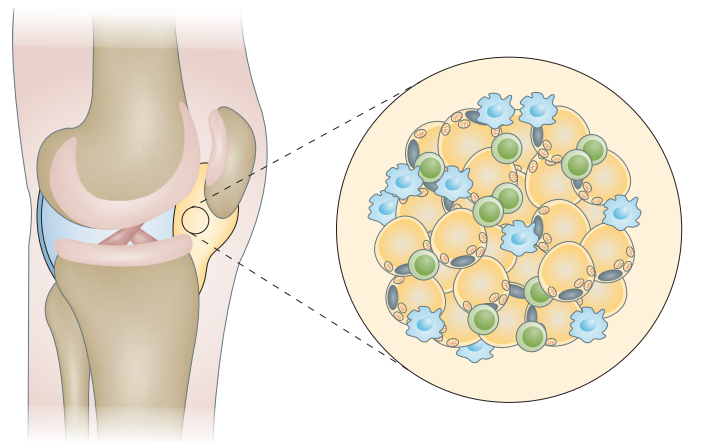

Macmillan Publishers Limited the adipokines and cytokines secreted by these tissues were determined.

As expected, IFP tissue isolated from patients with RA contained more inflammatory cells than IFP tissue from patients with $\mathrm{OA}$, but the levels and types of adipocytokines secreted were not significantly different. These findings suggest that the infiltrating immune cells contribute little to the secretion of adipocytokines by the IFP. Although the number of mast cells was increased in IFP tissue of patients with RA compared with OA, the opposite finding was observed in synovial tissue. "This observation indicates a differential regulation and possible role of mast cells in the synovium," states Ioan-Facsinay.

Ioan-Facsinay highlights that this study is the first one to report on IFP tissue in RA and suggests that the IFP has potentially a different role in RA compared with OA. However, validation with more samples and in different disease stages is required.

Liesbet Lieben, Senior Editor, Nature Reviews Disease Primers

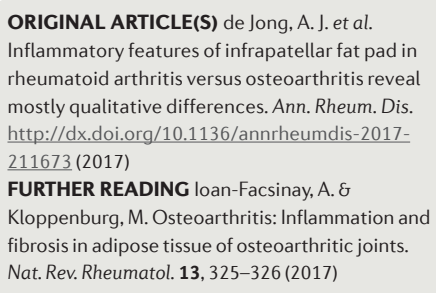

